\title{
Whole-Rock Fe Isotope \\ Compositions as a Tool for Exploring the Origin and Alteration of Hawaiian Shield-Stage Lavas
}

LAURA D. BILENKER ${ }^{1}$, DOMINIQUE Weis ${ }^{2}$, NiCOLE M.B. WILLIAMSON $^{2}$, KATHY GORDON ${ }^{2}$

${ }^{1}$ Auburn University, Department of Geosciences, Alabama, USA; LDB0036@auburn.edu

${ }^{2}$ Pacific Centre for Isotopic and Geochemical Research, EOAS, University of British Columbia, Vancouver, BC. dweis@eoas.ubc.ca; nwilliam@eoas.ubc.ca;

kgordon@eoas.ubc.ca

We report the most geographically extensive Hawaiian Fe isotope dataset to date with two primary goals: 1) to test the use of stable $\mathrm{Fe}$ isotopes as a tool to elucidate mantle processes (e.g., mixing of mantle plume components [1]); 2) to investigate whole-rock $\mathrm{Fe}$ isotope ratios as a record of primary igneous and secondary processes throughout the Hawaiian Islands. Hawai' $i$ is an excellent geological laboratory for assessing new isotopic methods as it is wellstudied and geochemically characterized. Although there have been $\mathrm{Fe}$ isotope studies done on individual systems within Hawai'i (e.g., the differentiation of Kīlauea Iki [2]) or focusing on mineral records of small-scale geochemical processes (e.g., diffusion recorded in olivine [3]), whole-rock $\mathrm{Fe}$ isotope compositions throughout the chain have not previously been measured and examined.

We analyzed 33 carefully selected samples of shield-stage tholeiitic basalt from 14 subaerial and submarine volcanoes already fully characterized geochemically (major and trace elements, $\mathrm{Pb}, \mathrm{Nd}, \mathrm{Hf}, \mathrm{Sr}$, and recently $\mathrm{Tl}$ isotopes) with both Kea and Loa trend compositions, spanning the past $\sim 5 \mathrm{Ma}$. This allows us to assess whether $\delta^{56} \mathrm{Fe}$ can potentially trace mineralogical differences in the source. Iron isotope results, reported to IRMM-14, range widely from a $\delta^{56} \mathrm{Fe}( \pm 2 \mathrm{SD})$ of $0.07 \pm 0.10 \%$ o to $0.54 \pm 0.01 \%$. Excluding five isotopically heavy samples from Mauna Kea, West Maui, Ko'olau Makapu'u, Wai'anae, and West Ka'ena, the range $(0.07 \%$ to $0.23 \%$ ) is tighter and consistently higher than average MORB $(\sim 0.10 \%)$. By considering the variations of the measured $\delta^{56} \mathrm{Fe}$ across the islands and relationships between these new data and pre-existing geochemistry, we have established what the bulk $\mathrm{Fe}$ isotope ratios of oceanic island basalts can reliably elucidate about mantle, magmatic, and secondary geologic processes.

[1] Nebel et al. 2019 EPSL 521 p. 60-67. [2] Teng et al. 2009 Science 320 p. 1620-1622. [3] Teng et al. 2011 EPSL 308 p. 317-324. 